Check for updates

Cite this: RSC Adv., 2017, 7, 36705

\title{
Hierarchical h-, m- and n-BiPO 4 microspheres: facile synthesis and application in the photocatalytic decomposition of refractory phenols and benzene $\uparrow$
}

\begin{abstract}
Xiaoxin Tian, (D) Tong Xu, ${ }^{b}$ Yunjian Wang ${ }^{b}$ and Sugang Meng (D) *bc
$\mathrm{BiPO}_{4}$ microspheres with three kinds of crystal phase $\left(\mathrm{h}-\mathrm{BiPO}_{4}, \mathrm{~m}-\mathrm{BiPO}_{4}\right.$ and $\left.\mathrm{n}-\mathrm{BiPO}_{4}\right)$ were prepared by a facile hydrothermal-calcination process. The crystalline phase, microstructures and photoelectrochemical properties were studied by various techniques. The results indicated that h-BiPO 4 could transform into $\mathrm{m}-\mathrm{BiPO}_{4}$ at $600{ }^{\circ} \mathrm{C}$. Interestingly, h-BiPO 4 accompanied with a little bit of $\mathrm{n}-\mathrm{BiPO}_{4}$ would transform into $\mathrm{n}-\mathrm{BiPO}_{4}$. After UV irradiation for $2 \mathrm{~h}$, conversion of $94.6 \%$ and a mineralization rate of $76.8 \%$ could be achieved on $\mathrm{n}-\mathrm{BiPO}_{4}$ for photocatalytic degradation of bisphenol $\mathrm{A}$, which is almost 1.33 times as high as that of $\mathrm{m}-\mathrm{BiPO}_{4}$ and 3.14 times that of $\mathrm{h}-\mathrm{BiPO}$. Moreover, the $\mathrm{n}-\mathrm{BiPO}_{4}$ also displayed the highest photocatalytic activity for degradation of other phenols (phenol and $p$ chlorophenol) in water and gaseous benzene. The enhancement of activity could be attributed to the improvement of the photogenerated electron-hole separation efficiency, which would be conducive to the formation of active species (hydroxyl radicals $\left({ }^{\circ} \mathrm{OH}\right)$ and superoxide radicals $\left({ }^{\circ} \mathrm{O}_{2}^{-}\right)$). The results suggest that $\mathrm{n}-\mathrm{BiPO}_{4}$ shows potential applications as an efficient and stable photocatalyst for the photocatalytic decomposition of persistent organic pollutants in water and in the gas phase.
\end{abstract}

Received 12th June 2017

Accepted 20th July 2017

DOI: $10.1039 / \mathrm{c} 7 \mathrm{ra06560d}$

rsc.li/rsc-advances under UV light irradiation. Moreover, the photocatalytic activity of $\mathrm{BiPO}_{4}$ could be enhanced remarkably by decreasing the grain size ${ }^{14}$ building phase junction, ${ }^{15}$ exposing high-energy facet ${ }^{16}$ or coupling with other semiconductors. ${ }^{17}$ It is not only efficient for decoloration of dyes, but also diverse in crystal phase (hexagon $\left(\mathrm{h}-\mathrm{BiPO}_{4}\right)$ and monoclinic phase with space group $P 2_{1} / \mathrm{m}(\mathrm{m}$ $\left.\mathrm{BiPO}_{4}\right)$ and $\left.P 2_{1} / n\left(\mathrm{n}-\mathrm{BiPO}_{4}\right)\right) \cdot{ }^{18-20}$ What's more, Zhu's group has demonstrated that $\mathrm{n}-\mathrm{BiPO}_{4}$ displayed higher activity than m$\mathrm{BiPO}_{4}$ and h-BiPO${ }_{4}$ due to the most distorted $\mathrm{PO}_{4}$ tetrahedron. ${ }^{20}$ Therefore, it is a promising photocatalyst and has much potential for environmental remediation in air and water by the direct absorption of light. ${ }^{21}$ However, the present studies mainly focus on the degradation of dyes (methylene blue, ${ }^{13-17}$ methyl orange $\mathrm{e}^{22}$ and rhodamine $\mathrm{B}^{17,23}$ ), while dyes are not suitable used to test the photocatalytic activity of photocatalyst because dyes have the dye-sensitized effect and an additional and more substantial problem. ${ }^{4}$ On the other hand, the colorless, highly toxic and refractory environmental endocrine disruptors and gaseous benzene were less reported. ${ }^{24}$ And the photocatalytic activity is not high enough, for example, less than $20 \%$ of benzene was degraded on $\mathrm{BiPO}_{4}$ photocatalyst under UV light irradiation for $12 \mathrm{~h}^{24 a}$ Therefore, fabrication of $\mathrm{BiPO}_{4}$ with excellent photocatalytic activity on degradation of environmental endocrine disruptors and gaseous benzene are significant foci on $\mathrm{BiPO}_{4}$ photocatalyst. It should be noted that the reason why the UV-light driven $\mathrm{BiPO}_{4}$ photocatalyst (the band-
453003, Henan, China

${ }^{b}$ College of Chemistry and Materials Science, Huaibei Normal University, Huaibei 235000, Anhui, China. E-mail: mengsugang@126.com; Fax: +86-561-3090518; Tel: +86-561-3802235

${ }^{c}$ Anhui Key Laboratory of Energetic Materials, Huaibei 235000, Anhui, China

$\dagger$ Electronic supplementary information (ESI) available. See DOI: 10.1039/c7ra06560d 
gap energies are in the range of 3.8-4.6 eV) was chosen in our work is not only because what we have introduced on the above but also because UV-light driven photocatalysis has potential use in the actual water industry. ${ }^{3}$ This is primarily due to the exorbitant occupied area that would result in replacing UV lamp reactors with solar irradiation. For instance, how much solar collection area is required to replace one $1000 \mathrm{~W}$ mercury lamp? $2.6 \mathrm{~m}^{2}$ of solar exposure would be needed to achieve the treatment power of one lamp. If for industrialization, this area would quickly add up due to the energy input requirements. ${ }^{3}$

Herein, $\mathrm{BiPO}_{4}$ with three different crystal phases (h-BiPO $\mathrm{m}-\mathrm{BiPO}_{4}$ and $\mathrm{n}-\mathrm{BiPO}_{4}$ ) and similar morphology (spherically hierarchical structure) were controllably synthesized by a facile hydrothermal-calcination method. Various characterization techniques were carried out on the as-prepared $\mathrm{BiPO}_{4}$ to obtain the information of crystal phase, micro-structure and optical properties. Bisphenol A (BPA) was selected as a model pollutant, because it is a representative material among environmental endocrine disruptors, ubiquitous in natural water, colorless, hard to be decomposed and has attracted much attention in recent years. ${ }^{25-27}$ For example, A. Omoike reported Heliscus lugdunensis, an aquatic fungus, could degrade over $70 \%$ of BPA after 12 days (microorganism method). ${ }^{27 c}$ Zhu's group reported that the maximum adsorption capacity of graphene for decontamination of BPA could reach up to $128 \mathrm{mg} \mathrm{g}^{-1}$, whereas the adsorption capacity of graphene is sensitive to $\mathrm{pH}$ and temperature of the solution (adsorption method). ${ }^{27 d}$ For photocatalytic method, although some photocatalysts such as $\mathrm{Pd} /$ mpg- $\mathrm{C}_{3} \mathrm{~N}_{4}$ (ref. $27 a$ ) and $\mathrm{Ag}_{3} \mathrm{PO}_{4}$ (ref. 27b) exhibited high activity with $93.9 \%$ and $100 \%$ of BPA removal from the solution within $180 \mathrm{~min}$ and $10 \mathrm{~min}$, respectively. The removal efficiency of noble metal-free photocatalysts is still low. For instance, only $6 \%$ and $6.7 \%$ of BPA was degraded over $\mathrm{g}-\mathrm{C}_{3} \mathrm{~N}_{4}$ and $\mathrm{TiO}_{2}$ after irradiation for $180 \mathrm{~min}$, respectively. ${ }^{27 a}$ Therefore, it calls for the development of more economical, powerful and durable photocatalyst for the removal of BPA. Up to now, there is scarce report about $\mathrm{BPA}$ degradation over $\mathrm{BiPO}_{4}$ photocatalyst. The results showed that $\mathrm{n}-\mathrm{BiPO}_{4}$ photocatalyst displayed the highest activity and separation efficiency of photogenerated electronhole pairs among these three $\mathrm{BiPO}_{4}$ photocatalysts. Moreover, the mechanism of influence on the activity of $\mathrm{BiPO}_{4}$ photocatalyst was also discussed. This work attempts to explore the potential application of $\mathrm{BiPO}_{4}$ for photocatalytic degradation of refractory phenols (BPA, including phenol and 4-chlorophenol (4-CP)) and decomposition of benzene in the gas phase.

\section{Experimental}

\subsection{Synthesis}

All the chemicals used in this work were analytical grade reagents without any further purification. In a typical synthesis, $1.03 \mathrm{~g}$ polyphosphoric acid and $0.97 \mathrm{~g}$ bismuth nitrate were successively dissolved in $20 \mathrm{~mL}$ deionized water. Then, the resulting solution dealt with two different heating ways to get $\mathrm{BiPO}_{4}$ samples. The first one is hydrothermal way that the beaker was heated to $160{ }^{\circ} \mathrm{C}$ and kept at this temperature for $1 \mathrm{~h}$, which was marked with $\mathrm{S}-\mathrm{OH}$. The second was heated by microwave (rated output of microwave is $800 \mathrm{~W}$ ), denoted as SMH. All the obtained $\mathrm{BiPO}_{4}$ samples (S-OH and S-MH) were washed several times with distilled water and fully dried at $80^{\circ} \mathrm{C}$ in oven. For further analysis, the prepared products S-MH and $\mathrm{S}-\mathrm{OH}$ were calcined in a muffle furnace at $600{ }^{\circ} \mathrm{C}$ for $2 \mathrm{~h}$. The obtained samples were called S-MHT and S-OHT, respectively.

\subsection{Characterization}

X-ray powder diffraction (XRD, Bruker D8 Advance, $\mathrm{Cu} \mathrm{K} \alpha$ radiation) was used to characterize the crystalline and phase constitutions of the samples. The morphology was analyzed by scanning electron microscopy (SEM, FEL Noval NanoSEM 230). Transmission electron microscopy (TEM) and high-resolution transmission electron microscopy (HRTEM) images were taken on a JEOL-2100 electron microscope operating at an accelerating voltage of $200 \mathrm{kV}$. The UV-vis diffuse reflection spectroscopy (DRS) patterns were measured by a Hitachi UV-365 spectrophotometer equipped with an integrating sphere, and $\mathrm{BaSO}_{4}$ as a reference sample coated standard pattern. The photoluminescence (PL) spectra were recorded on a JASCO FP6500 with an excitation wavelength of $256 \mathrm{~nm}$. The photoelectrochemical analysis was performed in a conventional three-electrode cell (CHI-660E, Chenhua Instruments Co., Shanghai, China), using a Pt wire and an $\mathrm{Ag} / \mathrm{AgCl}$ electrode as the counter electrode and reference electrode, respectively. The working electrode was prepared on indium-tin oxide (ITO) glass which was covered by $0.5 \mathrm{~cm} \times 0.5 \mathrm{~cm}$ samples. The electrolyte was $0.1 \mathrm{M} \mathrm{KCl}$ aqueous solution containing $0.01 \mathrm{M} \mathrm{K}_{3}\left[\mathrm{Fe}(\mathrm{CN})_{6}\right]-$ $\mathrm{K}_{4}\left[\mathrm{Fe}(\mathrm{CN})_{6}\right]$.

\subsection{Photocatalytic tests}

The photocatalytic activities of the synthesized samples were tested by the degradation of phenol, $p$-chlorophenol (4-CP) and bisphenol A (BPA) aqueous solution and degradation of gaseous benzene $\left(\mathrm{C}_{6} \mathrm{H}_{6}\right)$. The photocatalytic reaction system has been reported in our previous work. ${ }^{\mathbf{1 2}}$ The degradation of phenols was operated in a tubular reactor, which was surrounded by a water cooling jacket. A low pressure mercury UV light (Hshaped, $16 \mathrm{~W}$, a monochromatic emission at $254 \mathrm{~nm}$ ) was assembled at the center of the tubular reactor. $0.1 \mathrm{~g}$ sample was put into $150 \mathrm{~mL}$ phenol, $p$-chlorophenol or bisphenol A aqueous solution (20 mg L $\mathrm{m}^{-1}$ ) and then magnetically stirred in dark for $30 \mathrm{~min}$ to establish an adsorption-desorption equilibrium. After that, a $4 \mathrm{~mL}$ solution was sampled at various illumination time intervals and analyzed through a UV-vis spectrophotometer (Persee TU-1950). Photocatalytic degradation of benzene was carried out in a fixed-bed tubular quartz reactor $(250 \mathrm{~mm} \times$ $4 \mathrm{~mm}$ ), in which $0.1 \mathrm{~g}$ sample mixed evenly with $1 \mathrm{~g} \mathrm{50-70} \mathrm{mesh}$ high purity quartz sands was loaded, surrounded by four UV$254 \mathrm{~nm}$ lamps (TUV 6W/G6 T5, Philips) and operated in a singlepass mode. Benzene vapor with a constant concentration of 250 ppm was supplied by a gas cylinder (Dalian Da'te gas Co. China) and fed to the sample a total flow rate of $30 \mathrm{~mL} \mathrm{~min}{ }^{-1}$. The reactor temperature was kept at $30 \pm 1{ }^{\circ} \mathrm{C}$ by an air-cooling system and circulating water. Simultaneous determination of the concentrations of residual $\mathrm{C}_{6} \mathrm{H}_{6}$ and generated $\mathrm{CO}_{2}$ was 
performed on an online gas chromatograph (Agilent 7820A) with a flame ionization detector (FID) and a thermal conductivity detector (TCD), respectively.

\section{Results and discussion}

\subsection{Characterization}

Fig. 1 shows the XRD patterns of S-MH, S-MHT, S-OH, S-OHT and the standard diffraction peaks of h-BiPO ${ }_{4}$ (JCPDS 451370), $\mathrm{m}-\mathrm{BiPO}_{4}$ (JCPDS 43-0637) and n-BiPO 4 (JCPDS 15-0767). It can be seen that the crystalline phase of $\mathrm{S}-\mathrm{MH}$ is hexagonal phase with the main diffraction peaks at about $14.6^{\circ}, 20.1^{\circ}$, $25.5^{\circ}, 29.5^{\circ}, 31.3^{\circ}$ and $41.8^{\circ}$, which could be indexed to the (100), (101), (110), (200), (102) and (211) planes of h-BiPO respectively. No impurity peaks are found, indicating high purity of the sample S-MH. After calcination at high temperature, the crystalline phase of S-MHT is converted into m-BiPO and all the diffraction peaks of S-MHT are in good agreement with $\mathrm{m}_{-} \mathrm{BiPO}_{4}$. However, the sample $\mathrm{S}-\mathrm{OH}$ synthesized by a hydrothermal method is a mixture of h-BiPO 4 and n- $-\mathrm{BiPO}_{4}$. The peaks at $14.6^{\circ}$ and $20.1^{\circ}$ belong to (100) and (101) planes of h- $\mathrm{BiPO}_{4}$ can be observed obviously. It is clear that the XRD pattern of S-OHT corresponds to n- $\mathrm{BiPO}_{4}$ can be obtained by calcination of $\mathrm{S}-\mathrm{OH}$ at $600{ }^{\circ} \mathrm{C}$, and no impurity peaks are found. It is interesting to find that the $\mathrm{h}-\mathrm{BiPO}_{4}(\mathrm{~S}-\mathrm{MH})$ is easily transformed into m-BiPO 4 (S-MHT). But if it is a mixture of $\mathrm{h}-\mathrm{BiPO}_{4}$ and $\mathrm{n}-\mathrm{BiPO}_{4}(\mathrm{~S}-\mathrm{OH})$, it would be converted into n- $\mathrm{BiPO}_{4}$ (S$\mathrm{OHT})$. The existence of $\mathrm{n}-\mathrm{BiPO}_{4}$ would play the part of seed crystal. Moreover, the sharp and intense XRD peaks suggest that the as-prepared samples S-MH, S-MHT and S-OHT are wellcrystallized.

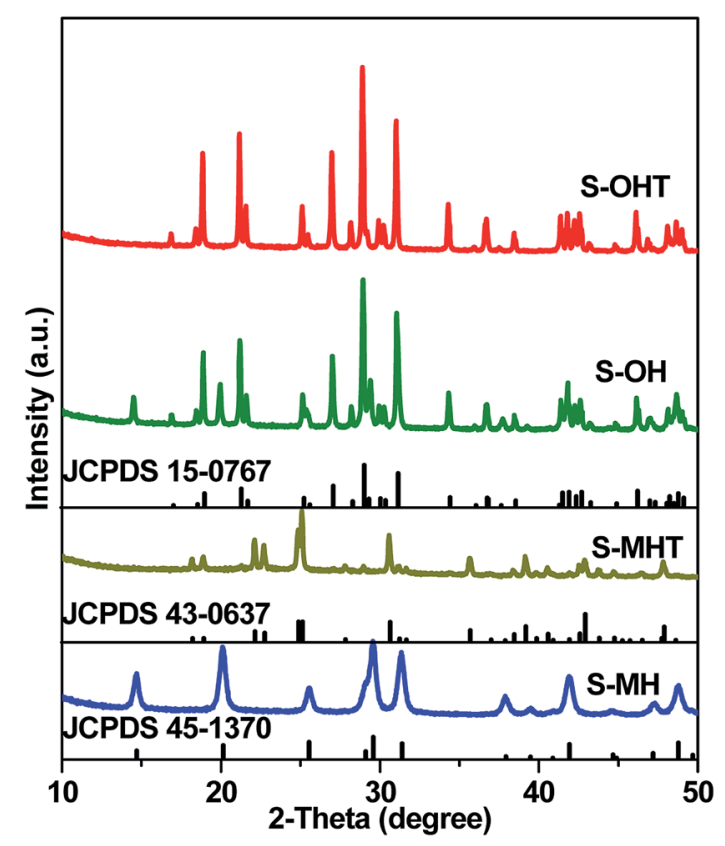

Fig. 1 XRD patterns of the as-synthesized S-MH, S-MHT, S-OH, S$\mathrm{OHT}$, together with the standard patterns of $\mathrm{h}-\mathrm{BiPO}_{4}$ (JCPDS 45 1370), $\mathrm{m}-\mathrm{BiPO}_{4}$ (JCPDS 43-0637) and n- $\mathrm{BiPO}_{4}$ (JCPDS 15-0767).
The morphology, particle size and micro-structure of the as-prepared samples were investigated by SEM and TEM (Fig. 2). As shown in Fig. 2a and e, the morphology of S-MH is the solid sphere with the diameter of 1-3 $\mu \mathrm{m}$, which is further composed of tiny nanoparticles. After heat treatment of S-MH, $\mathrm{S}-\mathrm{MHT}$ is also kept sphere shape, while its surface is rugged (Fig. $2 \mathrm{~b}$ and $\mathrm{f}$ ). This may be caused by sintering of tiny S-MH nanoparticles under high temperature calcination. HRTEM images of S-MH (Fig. 2i) and S-MHT (Fig. 2j) display the resolved lattice spacings of $0.28 \mathrm{~nm}$ and $0.32 \mathrm{~nm}$, which corresponding to the $d$-spacing values for (102) plane of h-BiPO and (101) plane of $\mathrm{m}-\mathrm{BiPO}_{4}$, respectively. It is in good agreement with the XRD results. For S-OH, its morphology is very interesting. As shown in Fig. $2 \mathrm{c}$ and g, the shape of S-OH is like sea urchin. It shows spherically hierarchical micro-structure, which is built by some connected nanoparticles, some nanorods like needle inserted into the sphere partly and pores. While for S-OHT (Fig. $2 \mathrm{~d}$ and $\mathrm{h}$ ), the sphere is different from S$\mathrm{OH}$. It is composed of nanorods not just in the surface, but some shortly scattered nanorods inside sphere, and some spheres are broken. From Fig. 2k and 1, it can be observed that the fringe spacings detected at nanorods of S-OH and S-OHT are about $0.32 \mathrm{~nm}$ and $0.47 \mathrm{~nm}$, corresponding to the (200) and (011) lattice planes of $\mathrm{n}-\mathrm{BiPO}_{4}$, respectively. In addition, the lattice fringes of S-OHT are very clear, indicating high degree of crystallinity. It is in good agreement with the results of the XRD analysis. Based on XRD and the morphology transformation analysis between $\mathrm{S}-\mathrm{OH}$ and $\mathrm{S}-\mathrm{OHT}$, it can be concluded that the nanoparticles with hexagonal phase in S$\mathrm{OH}$ would be transformed into nanorods with monoclinic phase after calcination at $600{ }^{\circ} \mathrm{C}$. S-OHT is the pure monoclinic phase of $\mathrm{BiPO}_{4}$ with $\mathrm{P}_{1} / n$ space group, lattice constants $a=6.752, b=6.933$ and $c=6.468 \AA$, and the spherically hierarchical micro-structure is composed of some shortly scattered nanorods. S-MH and S-MHT both exhibit the solid sphere shape, which is constituted by tiny and sintered nanoparticles, respectively. While $\mathrm{S}-\mathrm{MH}$ is the pure hexagonal phase of $\mathrm{BiPO}_{4}$ with $P 3_{1} 21$ space group and lattice constants $a=6.986, b=6.986$ and $c=6.475 \AA$ A $\mathrm{S}$-MHT is the pure monoclinic phase of $\mathrm{BiPO}_{4}$ with $P 2_{1} / \mathrm{m}$ space group and lattice constants $a=4.883, b=7.069$ and $c=4.704 \AA$.

Fig. 3 shows the UV-vis DRS of S-MH, S-MHT and S-OHT. The absorption edges of these three samples all occur at about $275 \mathrm{~nm}$. The band gap energy $\left(E_{\mathrm{g}}\right)$ is calculated via the Tauc equation, ${ }^{28-30}(\alpha h \nu)^{n}=A\left(h \nu-E_{\mathrm{g}}\right)$, where $A, \alpha, h$ and $\nu$ are proportionality constant, absorption coefficient, Planck constant and light frequency, respectively. The value of the exponent $n$ is decided from the properties of the transition in a semiconductor. ${ }^{21,30}$ Monoclinic $\mathrm{BiPO}_{4}$ (S-MHT and S-OHT) is an indirect band semiconductor, the value of $n$ is 0.5 . While hexagonal $\mathrm{BiPO}_{4}(\mathrm{~S}-\mathrm{MH})$ is direct, the value of $n$ is 2 . As shown in the inset of Fig. 3, the band gaps of S-MH, S-MHT and S-OHT are about $4.65,4.54$ and $4.49 \mathrm{eV}$, respectively. The difference among the band gaps of these three samples may be caused by their electronic structural difference limited by the crystalline phase, as also reported by Zhu's group ${ }^{21}$ and observed in anatase and brookite titanium dioxide. ${ }^{31}$ 


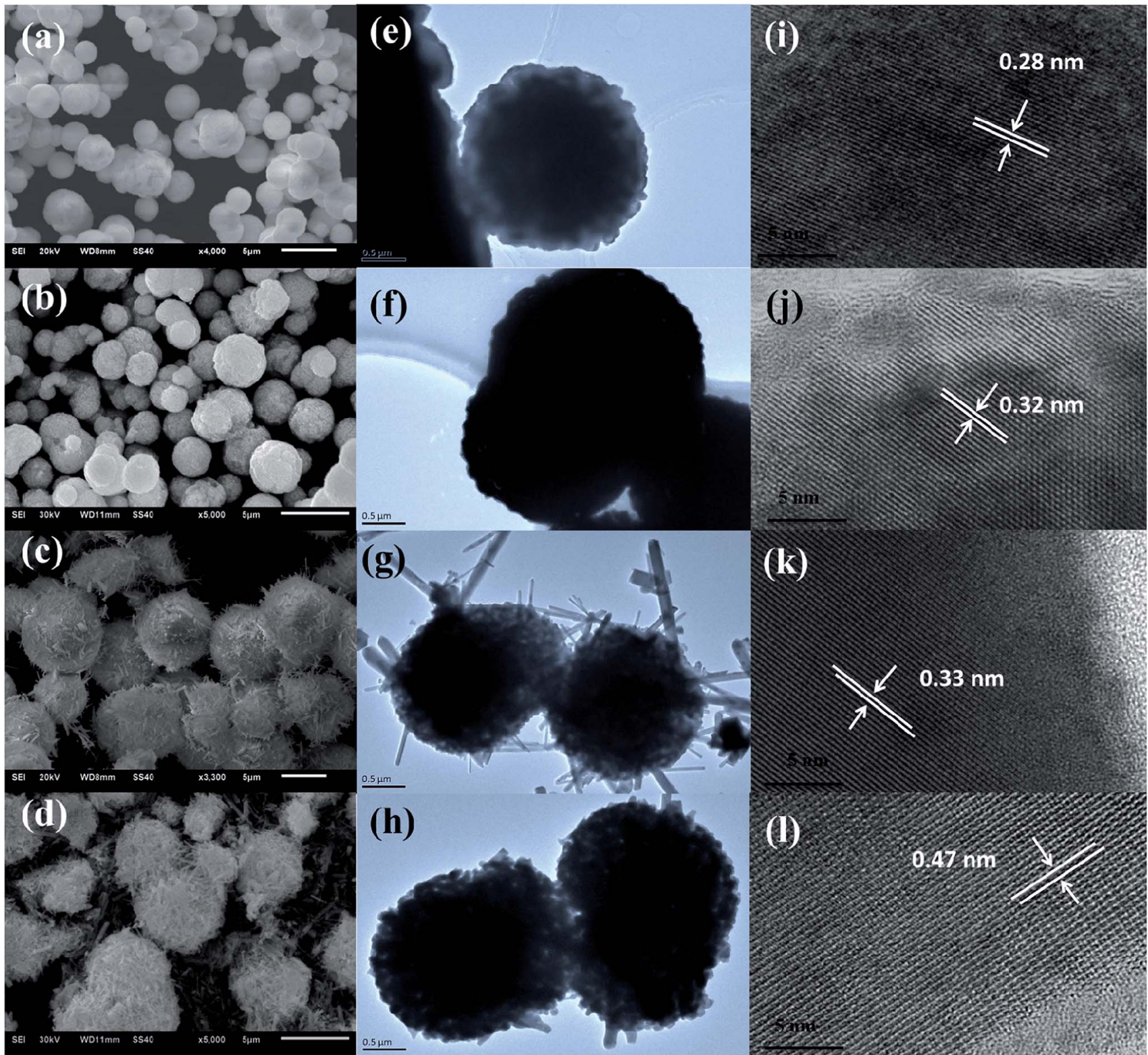

Fig. 2 (a-d) SEM, (e-h) TEM and (i-l) HRTEM images of the as-synthesized $(a, e, i) S-M H,(b, f, j) S-M H T,(c, g, k)$ S-OH and (d, h, l) S-OHT.

\subsection{Photocatalytic properties}

The photocatalytic activities of the as-prepared S-MH, S-MHT and S-OHT were tested by photocatalytic degradation of BPA, phenol and 4-CP under UV light irradiation. To investigate the effect of the amount of photocatalyst on the photodegradation efficiency of BPA, experiments performed (Fig. S1†) with different amount of $\mathrm{n}-\mathrm{BiPO}_{4}$ exhibited that the photocatalytic efficiency increases with an increase in n-BiPO ${ }_{4}$ amount up to $0.15 \mathrm{~g}$, and is then decreased. A similar phenomenon had been reported by others when studying photocatalytic degradation of dyes, ${ }^{32}$ and it can be explained in terms of availability of active sites on the catalyst surface and the penetration of light into the suspension. ${ }^{32}$ To further study the activity of n-BiPO ${ }_{4}$ for photocatalytic degradation of low concentration of BPA, the influence of the BPA concentration was investigated and shown in
Fig. S2. $\uparrow$ The results showed that the as-prepared n-BiPO 4 could effectively photocatalytic degrade different concentrations of $\operatorname{BPA}\left(5,10,15\right.$ and $\left.20 \mathrm{mg} \mathrm{L}^{-1}\right)$. Additionally, $150 \mathrm{~mL}$ BPA with concentration of $5 \mathrm{mg} \mathrm{L}^{-1}$ could be eliminated completely over n- $-\mathrm{BiPO}_{4}(0.1 \mathrm{~g})$ within irradiation for $30 \mathrm{~min}$. Fig. 4a displays the degradation profiles of BPA with $\mathrm{BiPO}_{4}$ samples. After $120 \mathrm{~min}$ of irradiation, $55.5 \%, 87.9 \%$ and $94.6 \%$ of BPA are degraded by the S-MH, S-MHT and S-OHT photocatalysts, respectively. The outstanding activity of the $\mathrm{BiPO}_{4}$ is further detected by comparing the apparent reaction rate constants $(k)$. As shown in Fig. $4 \mathrm{~b}$, the degradation of BPA can be described by the pseudo first-order reaction kinetics, $\ln \left(C / C_{0}\right)=-k t$, where $C_{0}$ and $C$ are the initial concentration and the concentration at reaction time $t$, respectively. The $k \mathrm{~s}$ for the S-MH, S-MHT and S-OHT are estimated to be about $0.42,0.99$ and $1.32 \mathrm{~h}^{-1}$, respectively. The 


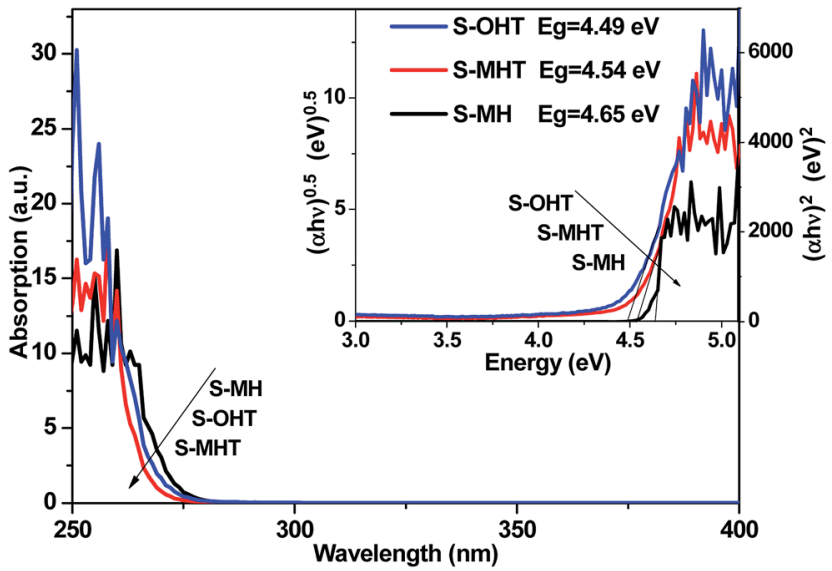

Fig. 3 UV-vis DRS spectra and bandgap energies (the inset) of the assynthesized S-MH, S-MHT, S-OH and S-OHT.

$k$ of S-OHT is 1.33-fold and 3.14-fold higher than that of S-MHT and S-MH. As we all known, degradation does not mean mineralization, because the original organic pollutants would be degraded to small organic molecules. Therefore, total organic carbon (TOC) technique was applied to further measure the mineralization of the solution, and the results are shown in Fig. 4c. It is clear that S-OHT exhibits the higher capacity (76.8\%) of mineralization for BPA than S-MHT $(65.2 \%)$ and S$\mathrm{MH}(25.1 \%)$. It means that the reactive species produced on n-BiPO ${ }_{4}$ photocatalyst not only can degrade BPA, but also can efficient decompose BPA into $\mathrm{CO}_{2}$. Moreover, the as-prepared S$\mathrm{OHT}$ is a stable photocatalyst in the process of photocatalytic degradation of BPA in water. After 3 cycles of the photocatalytic reaction, the photodegradation efficiency of BPA over the used

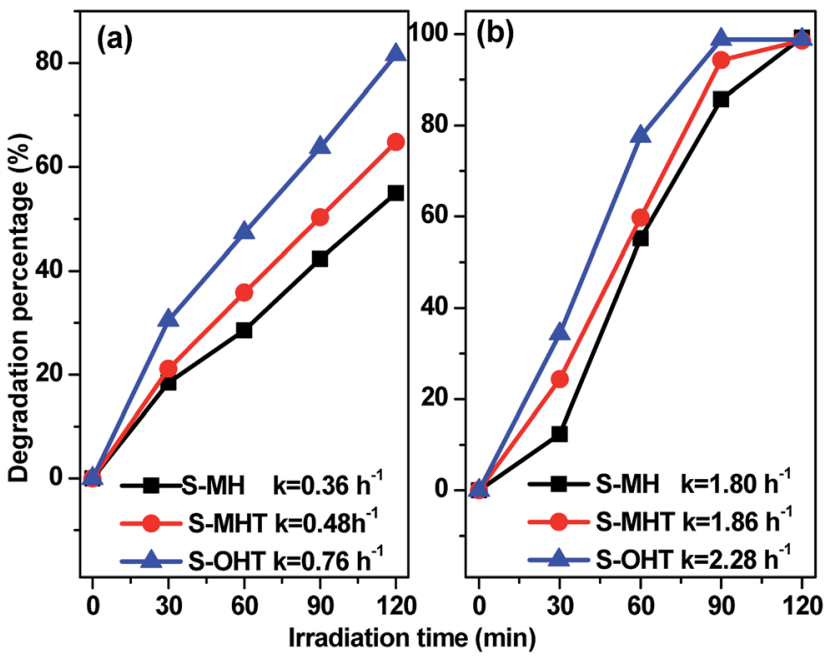

Fig. 5 Photocatalytic activities of the samples $(0.1 \mathrm{~g})$ for (a) phenol and (b) 4-CP degradation under UV light irradiation.

$\mathrm{S}-\mathrm{OHT}$ is similar to that over the fresh sample (Fig. 4d). The similar result was also reported by Zhu's group that n-BiPO ${ }_{4}$ is stable during the photocatalytic degradation of methylene blue. $^{13}$

To study the broad-spectrum activity of $\mathrm{BiPO}_{4}$ for other phenols, phenol and 4-chlorophenol (4-CP) were further selected as probe molecules to investigate the photocatalytic activities of the as-prepared $\mathrm{BiPO}_{4}$ samples. As shown in Fig. 5, whether the degradation of phenol or 4-CP over $\mathrm{BiPO}_{4}$ samples follows pseudo-first-order kinetics and the corresponding kinetic constants are showed in Fig. 5. Moreover, the photocatalytic activity for phenol and 4-CP degradation decreases in
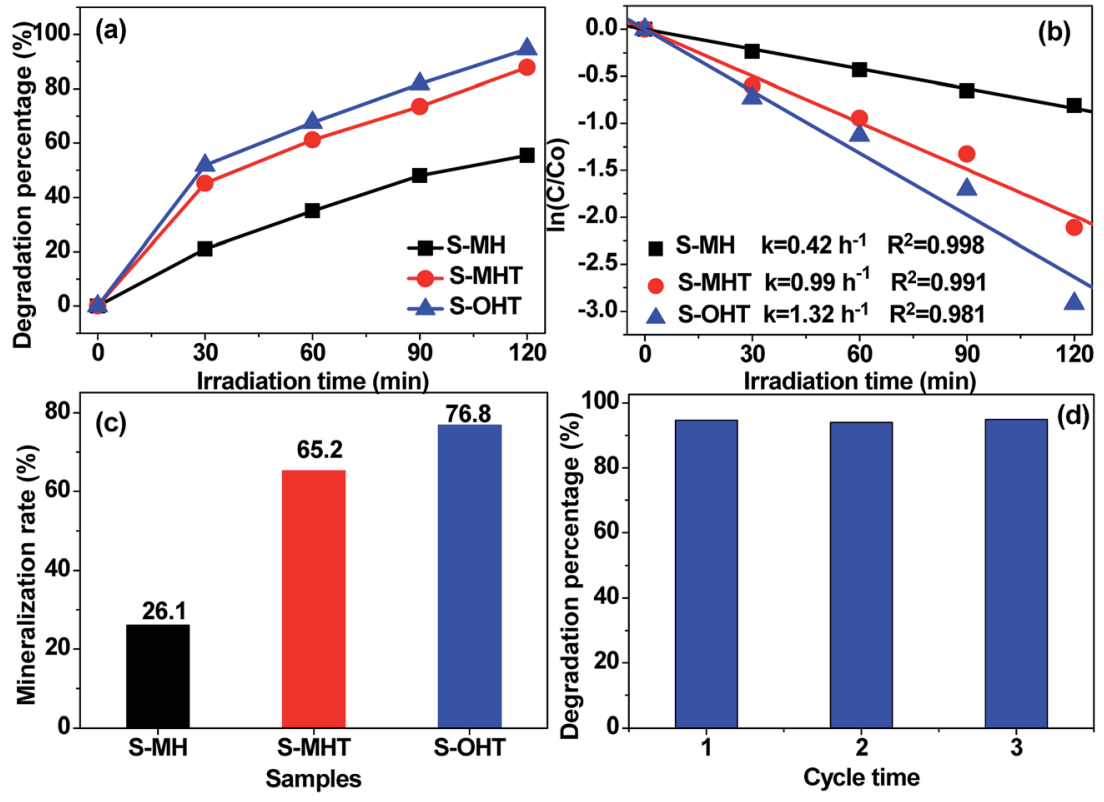

Fig. 4 (a) Photocatalytic degradation curves of BPA $\left(20 \mathrm{mg} \mathrm{L}^{-1}\right)$ for different samples $(0.1 \mathrm{~g})$ under UV light irradiation; (b) kinetic plots of In(C/ $\left.C_{0}\right)$ vs. irradiation time; (c) mineralization rate of BPA by different samples under UV light irradiation for 2 h; (d) cycling runs of S-OHT for BPA degradation under UV light irradiation. 
the order S-OHT > S-MHT > S-MH. The sequence is consistent with their performance for BPA degradation. In order to further illustrate the photocatalytic activity of the photocatalysts, the dark absorption test and the blank test were carried out. As shown in Fig. S3a, $\dagger$ the dark adsorption test in the absence of irradiation but with the catalysts showed that no significant change in the substrate concentration is found, and an adsorption-desorption equilibrium had been established after stir in dark for $30 \mathrm{~min}$. On the other hand, the blank tests (Fig. S3b $\dagger$ ) showed that $11.7 \%$ of BPA, $16.6 \%$ of phenol and $24.3 \%$ of 4 -CP were removed after irradiation for $2 \mathrm{~h}$ due to photo-induced self-photodegradation. However, compared with the distinctively photocatalytic activities of $\mathrm{n}-\mathrm{BiPO}_{4}(94.6 \%$ of BPA, $81.6 \%$ of phenol and $100 \%$ of $4-\mathrm{CP}$ were eliminated after irradiation for $2 \mathrm{~h}$ ), the presence of both photocatalyst and illumination is necessary for the effectively photocatalytic degradation of refractory phenols.

The photocatalytic degradation of phenols over S-OHT indicates that S-OHT has a great capability to decompose the benzene ring in the phenols. However, the degradation of benzene in the gas phase may be different to that in a liquid phase for the deficiency of water, which is crucial for the elimination of volatile organic compounds. To verify the validity of S-OHT on the photocatalytic decomposition of the benzene ring, the photocatalytic degradation behaviors of gaseous benzene by $\mathrm{BiPO}_{4}$ samples were carried out with the dry $\mathrm{O}_{2}$ atmosphere under the UV-light irradiation. As shown in Fig. 6, excluding S-MH, the degradation of benzene can be achieved on the S-MHT and S-OHT. The initial conversion of benzene on SMHT sample was about $80 \%$, with 500 ppm $\mathrm{CO}_{2}$ produced. However, after $10 \mathrm{~h}$ reaction time, the amount of $\mathrm{CO}_{2}$ gradually dropped to $105 \mathrm{ppm}$, and the conversion decreased to $13 \%$. Compared with S-MHT, the conversion of benzene over S-OHT sample was about $85 \%$ with 800 ppm $\mathrm{CO}_{2}$ produced during the first half hour. After irradiation for $7 \mathrm{~h}$, the benzene

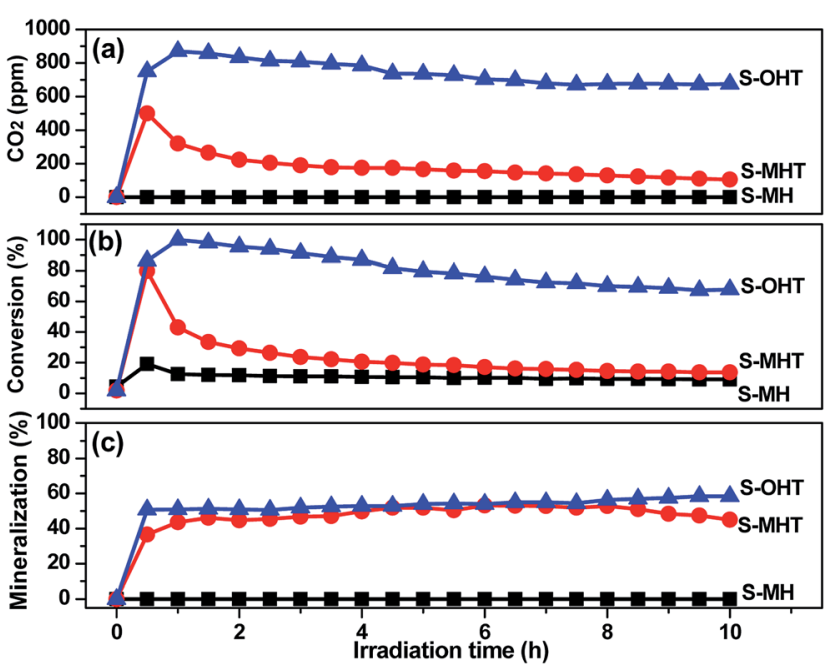

Fig. 6 (a) The production of $\mathrm{CO}_{2}$ and (b) the conversion and (c) mineralization efficiencies of $\mathrm{C}_{6} \mathrm{H}_{6}$ over prepared S-MH, S-MHT and S$\mathrm{OHT}$ as a function of irradiation time. conversion remained $67 \%$ with more than $675 \mathrm{ppm} \mathrm{CO}_{2}$ generated, and the average mineralization ratio of benzene was about 55\%, suggesting that most of benzene was mineralized to $\mathrm{CO}_{2}$. In the following $3 \mathrm{~h}$, the S-OHT sample displayed no obvious inactivation. Moreover, benzene could not be decomposed under UV-light irradiation, and the S-OHT sample didn't produce $\mathrm{CO}_{2}$ in the dark reaction. The results proved that the benzene ring was indeed decomposed by the S-OHT.

\subsection{Mechanism of photocatalysis}

In general, there are many factors influencing the photocatalytic activity of photocatalyst, such as the phase structure, light absorption, surface area, and the separation efficiency of photogenerated electron-hole pairs. ${ }^{1}$ It should be noted that the light source used in this work is monochromatic light with wavelength of $254 \mathrm{~nm}$. The light absorption of these three samples is all around $275 \mathrm{~nm}$, as shown in Fig. 3. Moreover, the BET surface area is all negligible $\left(<1 \mathrm{~m}^{2} \mathrm{~g}^{-1}\right)$. Therefore, it may be due to other factors that influence the activities of S-MH, SMHT and S-OHT. In the previous report, Zhu's group ${ }^{21}$ found that the highest photoactivity of $\mathrm{n}-\mathrm{BiPO}_{4}$ originates from the most distorted $\mathrm{PO}_{4}$ tetrahedron, not other factors such as photo absorption, BET surface area and the oxidation potential of photoexcited holes. The distorted $\mathrm{PO}_{4}$ tetrahedron facilitates the separation of photoexcited electron-hole pairs. Therefore, the photocatalytic activity of $\mathrm{BiPO}_{4}$ is deeply relying on the separation efficiency of photogenerated electrons and holes. To further confirm this summing-up, electrochemical impedance spectroscopy (EIS) and photoluminescence test (PL) were carried out in our experiments to investigate the differences of separation, transfer and recombination of the photoexcited electrons and holes between these samples. As previous studies, ${ }^{33,34}$ the diameters of the EIS plots under light irradiation are supposed to manifest the charge separation and transfer resistance across the solid-liquid junction in the electrode-electrolyte interface region. Besides, the smallest arc radius indicates most effective separation of the photoexcited electrons and holes, and vice versa. The typical EIS responses of $\mathrm{BiPO}_{4}$ with different crystal phase are presented in Fig. 7. The

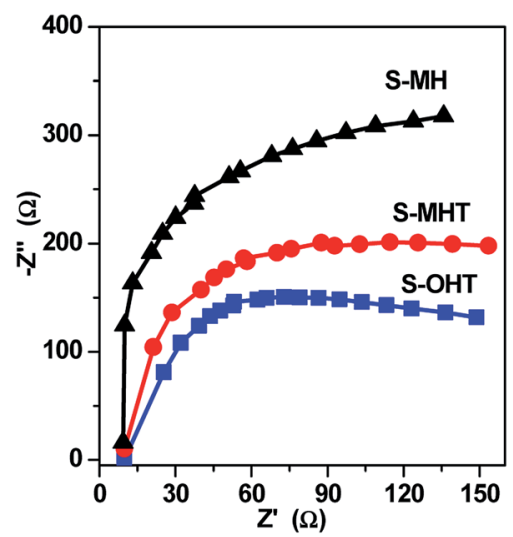

Fig. 7 EIS plots for the as-synthesized samples under UV-light irradiation. 
arc radiuses of prepared $\mathrm{BiPO}_{4}$ samples are different from each other. EIS data was analyzed in terms of an equivalent circuit model and the values of charge transfer resistance were about 330, 435 and $579 \Omega \mathrm{cm}^{-2}$ for $\mathrm{n}-\mathrm{BiPO}_{4}, \mathrm{~m}-\mathrm{BiPO}_{4}$ and h-BiPO${ }_{4}$, respectively. It indicates that $\mathrm{S}-\mathrm{OHT}$ with $\mathrm{n}-\mathrm{BiPO}_{4}$ phase possesses the highest efficiency of electron-hole separation among these three $\mathrm{BiPO}_{4}$ samples. This is also supported by the results of PL spectra, which can reflect the recombination rate of photoexcited electros and holes.

As well known, there are certain intrinsic relationships between the PL spectrum and photocatalytic activity of a semiconductor material according to the mechanisms of PL and photocatalysis. ${ }^{35}$ The lower the PL intensity, the higher the separation efficiency of photoexcited carriers, and thus the higher the photocatalytic activity. ${ }^{29,35}$ Fig. 8 presents the PL spectra excited at $255 \mathrm{~nm}$ wavelength at room temperature. A main emission peak centered at about $301 \mathrm{~nm}$ are observed for all samples. A weaker PL emission intensity than that of S-MH and S-MHT is produced on S-OHT, indicating that the recombination of the photoexcited electrons and holes is efficiently hampered on S-OHT. The result is in good agreement with the EIS. According to the above analysis, the photocatalytic activity difference between $\mathrm{h}-\mathrm{BiPO}_{4}, \mathrm{~m}-\mathrm{BiPO}_{4}$ and $\mathrm{n}-\mathrm{BiPO}_{4}$ is deeply relying on the separation efficiency of photogenerated electrons and holes. The results further confirm the previous report. ${ }^{21}$

It is well known that the photoexcited electrons and holes are the cornerstone of the photocatalysis. ${ }^{1}$ The efficient separation of photoexcited electrons $\left(\mathrm{e}^{-}\right)$and holes $\left(\mathrm{h}^{+}\right)$favors the production of hydroxyl radicals $\left({ }^{\circ} \mathrm{OH}\right)$ and superoxide radicals $\left({ }^{\circ} \mathrm{O}_{2}{ }^{-}\right)$, which are the primary and straightforward reactive species for the photocatalytic degradation of organic pollutants in the water. The photoexcited electrons and holes at the conduction band and valance band of $\mathrm{BiPO}_{4}$ can reduce $\mathrm{O}_{2}$ and oxidize $\mathrm{OH}^{-}$to form ${ }^{\circ} \mathrm{O}_{2}{ }^{-}$and ${ }^{\circ} \mathrm{OH}$, respectively. ${ }^{15}$ Moreover, ' $\mathrm{OH}$ may come from ${ }^{\circ} \mathrm{O}_{2}{ }^{-}$via chain reactions, and $\mathrm{H}_{2} \mathrm{O}_{2}$ is a significant intermediate species in the process. In order to confirm the presence of the photoactive radicals in the reaction system, following experiments were carried out. Terephthalic acid-photoluminescence (TA-PL), nitroblue tetrazolium (NBT) and $N, N$-diethyl- $p$-phenylenediamine (DPD) methods were used

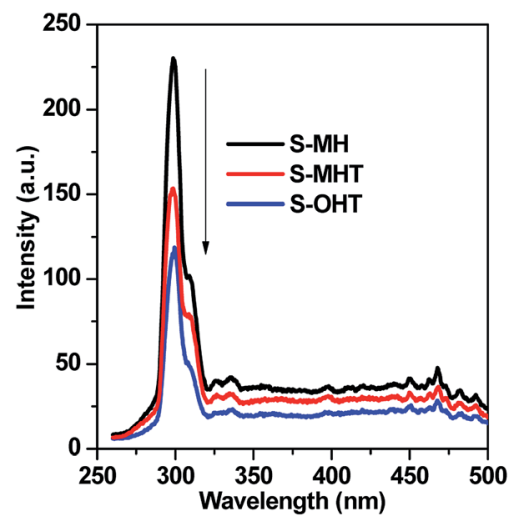

Fig. 8 Photoluminescence spectra of the as-synthesized samples (excitation wavelength was $256 \mathrm{~nm}$ ). to determine the photogenerated radical species ${ }^{\circ} \mathrm{OH}, \mathrm{O}_{2}{ }^{-}$and $\mathrm{H}_{2} \mathrm{O}_{2}$ over $\mathrm{BiPO}_{4}$ upon the irradiation of light, respectively. ${ }^{36-39}$

TA used as the indicator can readily react with the generated 'OH producing 2-hydroxyterephthalic acid (HOA), which has a good fluorescence. The intensity of PL implies the amount of generated ${ }^{\circ} \mathrm{OH}$ in the reaction system..$^{36,37}$ As shown in Fig. 9a, it is clear that the PL peaks located at about $426 \mathrm{~nm}$ for these three samples are observed, indicating that ${ }^{\circ} \mathrm{OH}$ is produced in the photocatalytic reaction process. Moreover, S-OHT displays the higher formation efficiency of ${ }^{\circ} \mathrm{OH}$ than S-MHT and S-MH. The formation of ${ }^{\circ} \mathrm{OH}$ order is S-OHT $>$ S-MHT $>$ S-MH, which is in accordance with the results of the photocatalytic activity and separation of photoexcited carriers tests. Nitroblue tetrazolium, exhibiting an absorption maximum at $259 \mathrm{~nm}$, was used for the analysis of ${ }^{\circ} \mathrm{O}_{2}{ }^{-}$. NBT can react with the formed ${ }^{\circ} \mathrm{O}_{2}{ }^{-}$in the water solution, and then its absorption peak would be reduced. ${ }^{38}$ Therefore, NBT method used as a simple approach for detection of ${ }^{\prime} \mathrm{O}_{2}{ }^{-}$has been widely adopted. As shown in Fig. 9b, the intensity of NBT at about $259 \mathrm{~nm}$ decreases gradually with the order: S-MH > S-MHT > S-OHT. It indicates that the concentration of NBT in the presence of S-OHT is reduced greatly. That is more ${ }^{\circ} \mathrm{O}_{2}{ }^{-}$is produced over S-OHT in the photocatalytic reaction process. Furthermore, the DPD method was employed for detecting the existence of $\mathrm{H}_{2} \mathrm{O}_{2} \cdot{ }^{39}$ As shown in Fig. 10, in the presence of either S-MH, S-MHT or S-OHT under UV-light irradiation, two clearly characteristic peaks of existence of $\mathrm{H}_{2} \mathrm{O}_{2}$ with absorption maxima at $510 \mathrm{~nm}$ and $550 \mathrm{~nm}$ are found. Moreover, the production of $\mathrm{H}_{2} \mathrm{O}_{2}$ decreases in the order S-OHT > S-MHT > S-MH. It is in line with the results of TA-PL experiment and the photocatalytic activity test.

In order to further understand the roles of the main oxidative species involved in the decomposition of BPA over $\mathrm{BiPO}_{4}$ photocatalyst, the trapping experiments of active species was performed, using isopropanol (IPA) as $\mathrm{OH}$ scavenger, ${ }^{40}$ ammonium oxalate (AO) as $\mathrm{h}^{+}$capturer, ${ }^{41}$ and benzoquinone
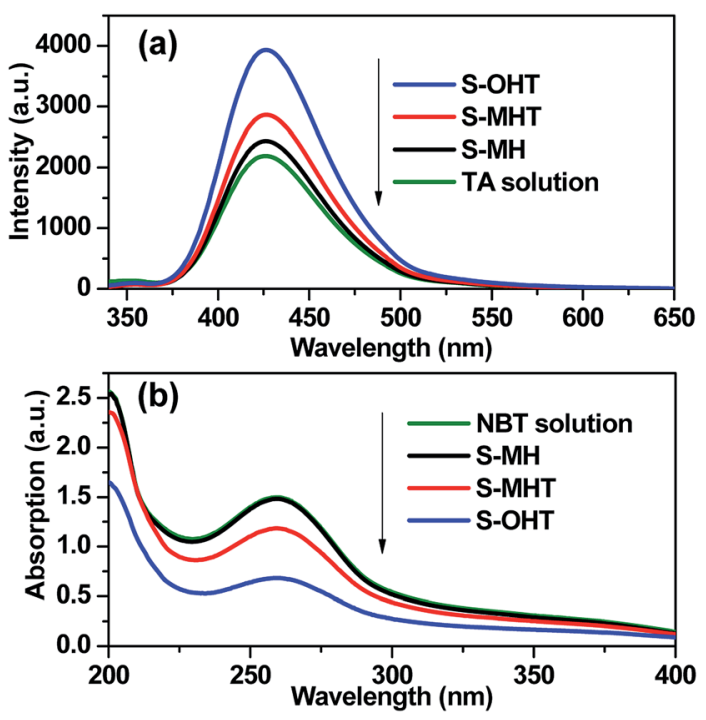

Fig. 9 (a) The photoluminescence emission spectra of TA solution and (b) the absorption of NBT solution in the presence of different samples under UV light irradiation. 


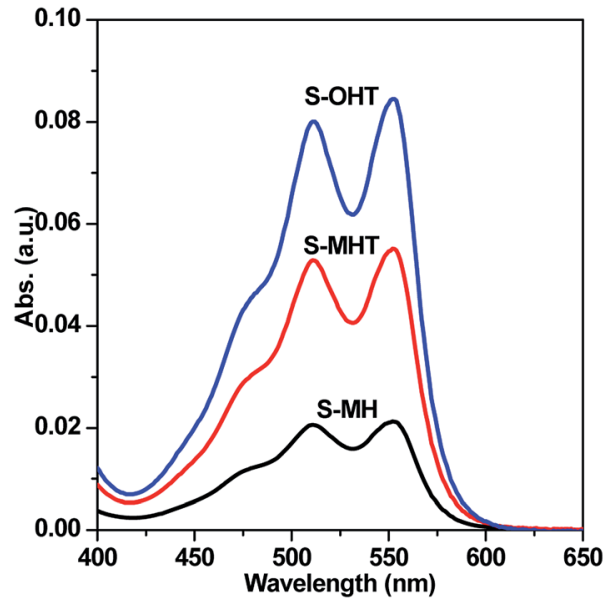

Fig. $10 \quad \mathrm{H}_{2} \mathrm{O}_{2}$ was detected by addition of $N, N$-diethyl-p-phenylenediamine and horseradish peroxidase to S-MH, S-MHT and S-OHT aqueous solution after UV light irradiation for $20 \mathrm{~min}$, respectively.

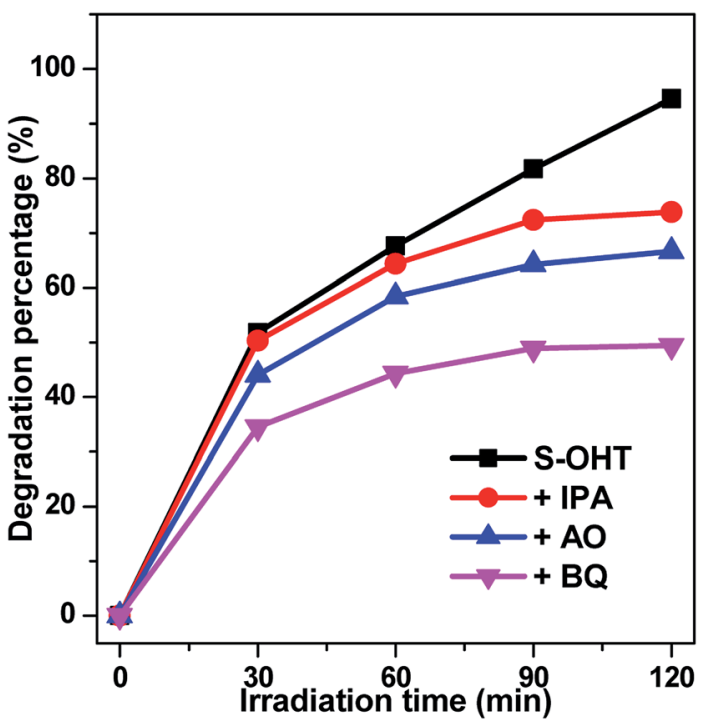

Fig. 11 Plots of photogenerated carriers trapping in the system of photocatalytic degradation of BPA on S-OHT.

(BQ) as ${ }^{\circ} \mathrm{O}_{2}{ }^{-}$scavenger. ${ }^{42}$ As shown in Fig. 11, the photocatalytic activity of S-OHT is obviously suppressed by adding AO or BQ, whereas slightly suppressed by ${ }^{\circ} \mathrm{OH}$ scavenger. It indicates that $\mathrm{h}^{+}, \mathrm{O}_{2}{ }^{-}$and ${ }^{\circ} \mathrm{OH}$ are all the oxidative species for the photocatalytic degradation of $\mathrm{BPA}$ over n-BiPO 4 photocatalyst, and the effect to BPA degradation from strong to weak follows the order of ${ }^{\circ} \mathrm{O}_{2}{ }^{-}, \mathrm{h}^{+}$and ${ }^{\circ} \mathrm{OH}$. Therefore, on the basis of the discussion and results above, a possible mechanism for the photocatalytic decomposition of phenols and benzene over n-BiPO 4 is proposed in Fig. S4.†

\section{Conclusions}

Sphere-like $\mathrm{BiPO}_{4}$ photocatalysts with h-BiPO, m-BiPO 4 and n$\mathrm{BiPO}_{4}$ crystal phases were controllably synthesized through a simple hydrothermal-calcination method, respectively. The n$\mathrm{BiPO}_{4}$ exhibited much higher photocatalytic activity towards degradation of BPA, phenol, 4-CP and benzene than h- $\mathrm{BiPO}_{4}$ and $\mathrm{m}-\mathrm{BiPO}_{4}$. The $\mathrm{BPA}$ degradation and mineralization rates could reach up to $94.6 \%$ and $76.8 \%$ under UV light irradiation for $2 \mathrm{~h}$, respectively. And the degradation efficiency is maintained at over $94 \%$ after three cycles. The excellent photocatalytic activity could be attributed to the distortion of $\mathrm{PO}_{4}$ tetrahedron, which improves the separation efficiency of the photoexcited electron-hole pairs and produces more oxidative species. During the photocatalytic process, effect of the oxidative specie to BPA degradation follows the order of ${ }^{\circ} \mathrm{O}_{2}{ }^{-}>\mathrm{h}^{+}>$ $\cdot \mathrm{OH}$.

\section{Acknowledgements}

This work was supported by the Natural Science Foundation of Anhui Province (1608085QB37), and the Collaborative Innovation Center of Advanced Functional Materials (XTZX103732016001).

\section{References}

1 M. R. Hoffmann, S. T. Martin, W. Choi and D. W. Bahnemann, Chem. Rev., 1995, 95, 69-96.

2 Y. Sun, S. Gao, F. Lei and Y. Xie, Chem. Soc. Rev., 2015, 44, 623-636.

3 E. L. Cates, Environ. Sci. Technol., 2017, 51, 757-758.

4 N. Barbero and D. Vione, Environ. Sci. Technol., 2016, 50, 2130-2131.

5 A. Fujishima and K. Honda, Nature, 1972, 238, 37-38.

6 J. H. Carey, J. Lawrence and H. M. Tosine, Bull. Environ. Contam. Toxicol., 1976, 16, 697-701.

7 X. Chen and S. S. Mao, Chem. Rev., 2007, 107, 2891-2959.

8 R. Daghrir, P. Drogui and D. Robert, Ind. Eng. Chem. Res., 2013, 52, 3581-3599.

9 M. Pelaez, N. T. Nolan, S. C. Pillai, M. K. Seery, P. Falaras, A. G. Kontos, P. S. M. Dunlop, J. W. J. Hamilton and J. A. Byrne, Appl. Catal., B, 2012, 125, 331-349.

10 X. C. Wang, K. Maeda, A. Thomas, K. Takanabe, G. Xin, K. Domen and M. Antonietti, Nat. Mater., 2009, 8, 76-80.

11 Z. G. Yi, J. H. Ye, N. kikugawa, T. Kako, S. Ouyang, H. Stuartwilliams, H. Yang, J. Y. Cao, W. J. Luo, Z. S. Li, Y. Liu and R. L. Withers, Nat. Mater., 2010, 9, 559-564.

12 X. Fu, J. Wang, D. Huang, S. Meng, Z. Zhang, L. Li, T. Miao and S. Chen, ACS Catal., 2016, 6, 957-968.

13 C. Pan and Y. Zhu, Environ. Sci. Technol., 2010, 44, 55705574.

14 C. Pan and Y. Zhu, J. Mater. Chem., 2011, 21, 4235-4241.

15 Y. Zhu, Y. Liu, Y. Lv, Q. Lin, D. Liu and Y. Zhu, J. Mater. Chem. A, 2014, 2, 13041-13048.

16 Q. Zhang, H. Tian, N. Li, M. Chen and F. Teng, CrystEngComm, 2014, 16, 8334-8339.

17 (a) B. Lu, X. Ma, C. Pan and Y. Zhu, Appl. Catal., A, 2012, 435, 93-98; (b) C. Pan, J. Xu, Y. Wang, D. Li and Y. Zhu, Adv. Funct. Mater., 2012, 22, 1518-1524; (c) Y. Liu, P. Zhang, H. Lv, J. Guang, S. Li and J. Jiang, RSC Adv., 2015, 5, 83764-83772. 
18 Y. Wang, X. Guan, L. Li and G. Li, CrystEngComm, 2012, 14, 7907-7914.

19 M. Zhao, L. Li, L. Yang, J. Zheng and G. Li, CrystEngComm, 2013, 15, 609-615.

20 C. Pan and Y. Zhu, Catal. Sci. Technol., 2015, 5, 3071-3083.

21 (a) C. Pan, D. Li, X. Ma, Y. Chen and Y. Zhu, Catal. Sci. Technol., 2011, 1, 1399-1405; (b) Y. Liu, Y. Zhu, J. Xu, X. Bai, R. Zong and Y. Zhu, Appl. Catal., B, 2013, 142, 561567.

22 P. Shan, C. Niu, D. Huang, G. Zeng and H. Zhang, RSC Adv., 2015, 5, 89105-89112.

23 (a) C. Pan, J. Xu, Y. Chen and Y. Zhu, Appl. Catal., B, 2012, 115, 314-319; (b) H. Lv, J. Guang, Y. Liu, H. Tang, P. Zhang, Y. Lu and J. Wang, RSC Adv., 2015, 5, 100625100632.

24 (a) B. Long, J. Huang and X. Wang, Prog. Nat. Sci.: Mater. Int., 2012, 22, 644-653; (b) X. Zou, C. Ran, Y. Dong, Z. Chen, D. Dong, D. Hu, X. Li and Y. Cui, RSC Adv., 2016, 6, 2066420670.

25 J. G. Hengstler, H. Foth, T. Gebel, P. J. Kramer, W. Lilienblum, H. Schweinfurth, W. Volkel, K. M. Wollin and U. Gundert-Remy, Crit. Rev. Toxicol., 2011, 41, 263-291.

26 L. N. Vandenberg, I. Chahoud, J. J. Heindel, V. Padmanabhan, F. J. R. Paumgartten and G. Schoenfelder, Environ. Health Perspect., 2010, 118, 10551070.

27 (a) C. Chang, Y. Fu, M. Hu, C. Wang, G. Shan and L. Zhu, Appl. Catal., B, 2013, 142, 553-560; (b) H. Katsumata, M. Taniguchi, S. Kaneco and T. Suzuki, Catal. Commun., 2013, 34, 30-34; (c) A. Omoike, T. Wacker and M. Navidonski, Chemosphere, 2013, 91, 1643-1647; (d) J. Xu, L. Wang and Y. Zhu, Langmuir, 2012, 28, 8418-8425.
28 M. A. Butler, J. Appl. Phys., 1977, 48, 1914-1920.

29 S. Meng, X. Ning, T. Zhang, S. Chen and X. Fu, Phys. Chem. Chem. Phys., 2015, 17, 11577-11585.

30 Y. F. Liu, Y. H. Lv, Y. Y. Zhu, D. Liu, R. L. Zong and Y. F. Zhu, Appl. Catal., B, 2014, 147, 851-857.

31 T. A. Kandiel, A. Feldhoff, L. Robben, R. Dillert and D. W. Bahnemann, Chem. Mater., 2010, 22, 2050-2060.

32 (a) N. Naneshvar, D. Salari and A. R. Khataee, J. Photochem. Photobiol., A, 2004, 162, 317-322; (b) M. S. T. Goncalves, A. M. F. Oliveira-Campos, E. M. M. S. Pinto, P. M. S. Plasência and M. J. R. P. Queiroz, Chemosphere, 1999, 39, 781-786.

33 B. L. He, B. Dong and H. L. Li, Electrochem. Commun., 2007, 9, 425-430.

34 H. Zhang, X. Lv, Y. Li, Y. Wang and J. Li, ACS Nano, 2010, 4, 380-386.

35 L. Jing, Y. Qu, B. Wang, S. Li, B. Jiang, L. Yang, W. Fu, H. Fu and J. Sun, Sol. Energy Mater. Sol. Cells, 2006, 90, 1773-1787.

36 J. C. Barreto, G. S. Smith, N. H. P. Strobel, P. A. McQuillin and T. A. Miller, Life Sci., 1994, 56, 89-96.

37 K. Ishibashi, A. Fujishima, T. Watanabe and K. Hashimato, J. Photochem. Photobiol., A, 2000, 134, 139-142.

38 B. H. J. Bielski and H. W. Richter, J. Am. Chem. Soc., 1977, 99, 3019-3023.

39 S. Meng, D. Li, X. Fu and X. Fu, J. Mater. Chem. A, 2015, 3, 23501-23511.

40 M. Sadakane, K. Sadaki, H. Kunioku, B. Ohtani, W. Ueda and R. Abe, Chem. Commun., 2008, 48, 6552-6554.

41 H. Kominami, A. Furusho, S. Murakami, H. Inoue, Y. Kera and B. Ohtani, Catal. Lett., 2001, 76, 31-34.

42 R. Palominos, J. Freer, M. A. Mondaca and H. D. Mansilla, J. Photochem. Photobiol., A, 2008, 193, 139-145. 